\title{
Convocation Address
}

\section{Clarence Wilfred de Silva}

\section{"If You Are Determined, No Bar is Too High!"}

Even though in my profession I interact with many students and academic professionals every day, I consider it an extraordinary delight and a special privilege to address directly the graduating students who are gathered here today. This is so because you are a very important group of people who are at the crossroads of: studentship and professional career; relative personal dependence and relative personal independence; holding relatively minor responsibility and anticipating relatively major responsibility; being shaped by the past and embarking on shaping the future; and so on. As I had said many times in the past, my heart rejoices to see your bright and young faces, filled with ambition, goals, and dreams, as I was many decades previous, while graduating from the then University of Ceylon, now University of Sri Lanka, Peradeniya. In this backdrop I may say that "I have been there!"

Coming from a generation of teachers, education is in my blood. When I enter any establishment of higher learning anywhere in the world, a sense of tranquility and respect flows into my mind, as if I am entering a temple or other place of worship. I hope that you feel the same way. The respect for learning and for the institutions of learning is a must for our intellectual growth and is an essential ingredient for a just and peaceful society.

Knowledge is a common thread that binds us all. One does not need university degrees to gain knowledge. Our very own Dr. Martin Wickramasinghe comes to my mind as the perfect example. Also, it reminds me of the fruit vendor in Fukuoka who fancied fuzzy logic; the plumber in Pittsburgh who pointed to Physics; the carpenter in Christchurch who was curious about control systems; or the mason in Morahela who was mesmerized by Mechatronics. Indeed, we should seek to teach others everything that we know. It was Lord Buddha who has asked us to do this selflessly without holding anything back-that is without retaining any "Guru Mushtiya." It is the best alms that 
anyone can offer. Also it was Lord Buddha who compared the knowledge that one possesses to a bunch of leaves in hand, and the knowledge yet to be gained to the leaves in an endless jungle. I am sure, other philosophers and religious leaders have conveyed similar messages. Nevertheless, I think it is the great American President and author of the Declaration of Independence, Mr. Thomas Jefferson who said it best: "He who knows best knows how little he knows" and "Lighting someone else's candle does not reduce the glow of one's own candle." I believe that Jefferson — an avid reader-was a student of Buddhism!

\section{Knowledge and intelligence are related but not synonymous.}

Someone once told me that people can be classified into the two groups "street smart" and "book smart." I disagreed, and we had a lengthy discussion on this issue. My point was that the human mind is very complex and it is impossible to categorize the smartness of nearly 7 billion people in the world into just two broad sets. Furthermore, there does not exist a precise and complete definition for intelligence. In fact it is what one observes from the exterior of an individual as "intelligent behavior" that facilitates one to classify the individual as "intelligent." This is called description through characterization. Couldn't it be possible, for example, for a very smart person to pretend to be "stupid"? Then without a precise definition, an accurate model, or a reasonable measuring technique, how is it possible to accurately determine the "level of intelligence" of a person, let alone the "type of intelligence?" I believe that no matter what definitions are constructed and what categories are put forth, any particular human may be assigned a "grade of membership" in any of these categories of intelligence, as defined in any conceivable way. That is where fuzzy logic will become in handy even though the time and the space do not permit me to elaborate on that here. Suffice it to say that what one observes as intelligent behavior has many manifestations and combinations thereof.

For example, even though sophisticated computers that are termed "intelligent machines" are available, at the basic or atomic level of implementation what a computer does is quite procedural and cannot be considered intelligent. Similarly, one may argue that the 20 billion neurons in a human brain perform operations that are hardly intelligent when taken individually. It is these same neurons, however, that govern the intelligent behavior of a human. In particular, the attributes of knowledge acquisition-making logical inferences, learning, and dealing with incomplete or qualitative information and uncertainty-are all associated with human intelligence. In summary, 
an intelligent system possesses one or more of the following characteristics and capabilities:

- Sensory perception

- Pattern recognition

- Learning and knowledge acquisition

- Inference from incomplete information

- Inference from qualitative or approximate information

- Ability to deal with unfamiliar situations

- Adaptability to new, yet related situations (through "expectational" knowledge)

- Inductive reasoning

- Common sense

- Display of emotions

- Inventiveness.

It should be clear then that knowledge and intelligence are related but not synonymous.

\section{This brings me to the topic of Dynamics of Intelligence}

Every day we come across information, for example, in the form of newspapers, radio and TV broadcasts, sensory data, books, charts, and computer files. Information itself does not represent knowledge. We have to "acquire" knowledge, say through experience and by learning. In this sense, information is subjected to a form of high-level processing when gaining knowledge, and hence we may interpret knowledge as structured information. Specialized and enhanced knowledge may be termed expertise. Here again, knowledge is subjected to high-level processing when acquiring expertise.

A simplified and qualitative model for the dynamics of intelligence is shown in Figure 1. This model illustrates the hierarchical nature of the associated processes as well. In the model of Figure 1, intelligent preprocessing is identified as the operation that converts information into knowledge and knowledge into expertise. A degree of intelligence is needed to carry out these preprocessing operations, and simultaneously the intelligence itself will be broadened or enhanced through preprocessing, as indicated by the bi-directional activity lines. Knowledge may be interpreted as "structured information" that is 
C.W. de Silva

acquired by an intelligent object, and expertise as "specialized knowledge." In this sense, preprocessing operations will perform structuring and acquisition of the information when gaining knowledge, and will specialize the knowledge when gaining expertise. Note that knowledge and expertise can depreciate, and be outdated or lost, in the absence of continuous usage, learning, and updating (i.e., intelligent preprocessing). The blocks of "Knowledge Dynamics" and "Expertise Dynamics" account for such appreciation and depreciation, in the simplified model given in Figure 1. Similarly, the block of "Intelligence Dynamics" allows for variations in the level of intelligence.

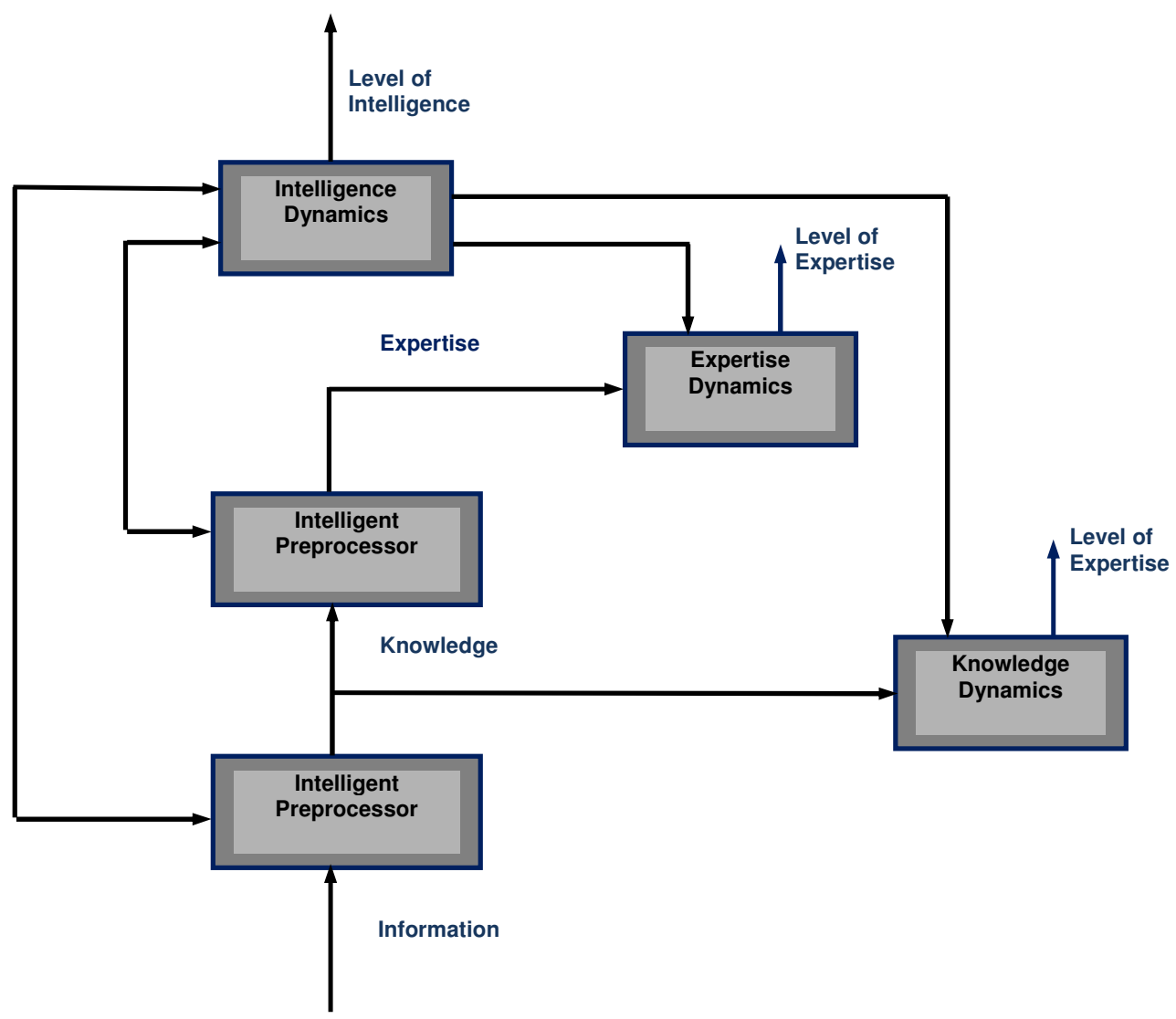

Figure 1 A Schematic Model for the Dynamics of Intelligence.

\section{Graduating Students, the smart beings that you are, you must resolve to overcome all barriers on your journey to progress!}

Some of you may be nervous of the challenges ahead, but let me assure you. No obstacle is insurmountable, no road is too long, and no bar is too high as long as you: Know your goals, are highly motivated and 
determined, carefully plan the ways to achieve them, and work relentlessly. You should be dedicated but be aware of the needs of the others around you; You should work vigorously yet know your limitations; You should question issues but should not be confrontational; You should be loyal but scrutinize when necessary; You should be firm on what you are confident of but be flexible to accommodate good ideas from others; and You should display the authority that you possess yet respect the authority of the others.

\section{You must repay the society for the benefits that you have derived from it.}

You may think that I am a hypocrite who enjoys the riches of a foreign country while having benefitted from my motherland. You should not rush to judge me in that manner. A very long time ago, with the ambition of entering the academic profession, I sought an Assistant Lecturer position in Sri Lanka, soon after obtaining my first degree. Unfortunately I did not succeed in that endeavor even though I had a first class honors degree and also had topped the entire batch of engineering in that year. Undeterred, I achieved my ambition through other means (hence my previous advice to you that no obstacle is insurmountable). However, I have tried to help Sri Lanka whenever feasible. My collaboration with Mr. P.D. Sarath Chandra, former Head of Mechanical Engineering at OUSL, in establishing the Mechatronics Program at OUSL is one such example. I have provided scholarships for Sri Lankan engineering students to obtain their Master's and Ph.D. degrees under my supervision at my university-University of British Columbia (UBC). Many of them have since returned to Sri Lanka and are serving the motherland admirably. Examples are: Dr. Lalith Gamage who founded SLIIT; Dr. Nalin Wickramarachchi, the former Head of Electrical Engineering at University of Moratuwa; and your own Mr. Duminda Wijewardane, a Lecturer at OUSL.

Also we have established a computer-based mentoring system called "Guna Nena Diriya" for students in a remote village of Badulla, to assist them with any problems that they may encounter in life and in education. With this system, the village students who had not used a computer before now have access to laptop computers, which have Internet access capabilities. They are now able to communicate with a selected group of mentors-Sri Lankan professionals who live throughout the world-and discuss any topic of interest with them. Also we have built a road and a hospital canteen in the same village.

I don't want to stop there. My goal is to establish a "telemedicine" link between the village of Ketawatta and the nearest hospital (in Migahakiula) which is five miles away and without a dependable 
public transportation system. The basic operation of the telemedicine facility will be as follows: A user (a possible patient) will walk into the computer room of the school, wear a convenient hand harness and push a button to initiate a session with a medical professional (a doctor or a nurse) at the hospital. The harness will acquire some vital data (e.g., body temperature, pulse rate, and blood pressure) of the user and make that information available to the medical professional at the remote hospital. Also voice and video links will be established between the patient and the medical professional (through microphones and web cameras). Through consultation and the sensory data the medical professional will make one of three decisions: 1 . The patient must come to the hospital immediately; 2 . The patient should visit the hospital when convenient (possibly on the next day); 3 . There is no need for the person to visit the hospital (further advice may be provided as well, such as: take an Asprin, drink some coriander water or tea and take rest). I believe that this will be a valuable service for rural villages in Sri Lanka which don't have proper hospital facilities.

\section{Treat your first job as your last.}

Your first job may shape you beyond your wildest imagination. Give it everything that you have. Venture into all possible opportunities that it may offer. It will shape you and your future as did your formal education. Going back to my past as an example, I recall that, while not giving up hope for an academic career I secured my first job as an Assistant Works Engineer in a private factory in Maharagama which manufactured consumer products of rubber, plastic, aluminum, and steel. Even though it was a major deviation from my student life I quite enjoyed the challenge. It offered me many avenues to gain experience in real-life engineering activities including installation, testing, and maintenance of machinery, development of new products, and even planning and supervision of the construction of a new building for expansion of the factory. Many pleasant and life-changing experiences during my two-year tenure there come to my mind. When my Chief Engineer offered me the factory bungalow at no rent, I grabbed the opportunity. Little did I realize that it was not an offer entirely with my wellbeing at heart. The factory operated three shifts and the engineers were available only during the day shift. During the other shifts, with the slightest technical problem, not to mention a machine breakdown, a foreman would come rushing into my residence seeking my advice. I would change my clothes, walk with him to the factory floor, examine the situation, and provide whatever advice I could give, with the limited knowledge and experience that I possessed at the time, to resolve the problem, short of calling the Chief Engineer. Soon I realized that the foremen were more knowledgeable and skilled than I was. They were just having fun while testing me, teasing me, and simply annoying me. 
I learned to respect them, learn from them, and be friendly with them, not hesitating to support them in their personal grievances as well. Eventually they stopped bothering me and managed to resolve all the factory-floor problems during off hours without calling for my intervention!

A particularly rewarding opportunity presented itself when I noticed the hazardous working conditions of the laborers (mostly women) who manually buffed (polished) the molded rubber parts using a type of grinding machine. The rubber dust was unbearable and presented a possible health hazzard, the monotony of the operation was unpleasant, and the productivity was rather poor. I discussed with my Chief Engineer and offered to design a simple machine that could automatically buff the parts in bulk while an exhaust system would safely remove the rubber dust from the machine environment. It was my first "Mechatronics" experience. In particular, the design involved the integration of an induction motor, gear transmission, emery-coated drum, motor controls, and plumbing. Even though my specialization for the bachelor's degree was mechanical engineering, I had studied electrical engineering in the first two years, and subsequently rudimentary industrial electronics. This knowledge would become very useful in this engineering adventure. The Chief Engineer quickly gave me his blessing for the project and also assigned me an old foreman who was lazy and known to idle most of the time. I somehow convinced the foreman to help make the project a success, promising him some financial inducement. He was rather enthusiastic after that and also was quite proud of his newly acquired stature as a machine designer and builder working hand in hand with a university-educated engineer. Soon the progress in the project was hampered by the union leadership of the factory who claimed that automation of the buffing process would lead to loss of jobs. Thankfully, the foreman who headed the factory union was friendly with me. After a long and somewhat acrimonious chat with him, I was able to convince him of the advantages of automation: we would remove people from a hazardous, tiring and monotonous task; we would increase the productivity, product quality and repeatability; with the increased revenues we could train the workers for more skilled jobs at higher pay; and we could hire more workers. We managed to design, build and operate several machines which automated the entire buffing process in the factory.

\section{To be rich, you don't need money.}

After leaving Sri Lanka for my graduate studies, my goal was to enter MIT. After completing my Master's degree at the University of Toronto, Canada and while awaiting admission to MIT, I moved to Cincinnati, Ohio. There, while completing a Master's degree in Aerospace 
Engineering, I did several jobs simultaneously: a part-time Instructor position in Physics at Miami University, Oxford, Ohio; a part-time Instructor position in Computer Programming at Southern Ohio College; and a night security guard position in the city. I enjoyed all these jobs even though the experiences were quite varied. I must note that when I was a student, the University of Ceylon did not have any computers and did not offer courses in programming languages. I had to self-study computer programming after I left Sri Lanka. My first teaching assignment at Southern Ohio College was in Machine Language Programming of computers which is far more difficult than high-level programming (in languages such as FORTRAN and C). The security guard position provided training in weapons that, thankfully, I never had to use, free food, physical exercise, and ample time to read. The income from my part-time jobs was more than enough for me to live a comfortable life. Also, I was able to help my parents back home in Sri Lanka with the extra money. I was even able to buy a decent car.

Later in life I made more money and acquired more comforts in life. However, I was happier when I had less material wealth. Someone once said that "if you think the money will make you happy, then you have never been rich." This too is in agreement with the Buddhist philosophy. In fact, the title of my convocation address at the University of Waterloo, Canada several years back was "To be Rich, You Don’t Need Money!"

I don't imply here that you should not strive to make money or acquire material comforts. My point is, earning money should not be the primary purpose in life. Select the job that will make you happy rather than the one that will provide the highest pay. Frankly, I would not be very unhappy if I had lost all my possessions as long as I had my health, knowledge, and family.

\section{Let me now address specifically the students who are graduating from the new Mechatronics Program at OUSL.}

You are familiar with the technical definition of Mechatronics. It talks about "synergy," "integration," "unification," "multidisciplinarity," and "optimization." I ask you to approach real-life non-technical problems as well from this viewpoint. I assure you that it will be rather rewarding and fulfilling, at least mentally. Do not worry about the scholarship that you lost to a less qualified person or the job that you did not get for no fault of your own. With determination, passion, dedication, and drive you are bound to succeed eventually. No bar is too high!

I am delighted that, under the leadership of Mr. P.D. Sarath Chandra, OUSL is the first university in Sri Lanka to formally offer academic 
programs in Mechatronics. I was proud to collaborate with him and his staff in developing these programs. My interest in Mechatronics was a consequence of necessity. When I was offered a Chair Professorship in Industrial Automation at the University of British Columbia in 1988, the research and development that entailed was essentially Mechatronics. Using the principles of integrated design of electromechanical systems, we were able to design and develop several automated machinery for the fish processing industry. It may be difficult to comprehend that such complex machinery could be designed, built, and tested in a university laboratory. Two examples are the "Automated Fish Processing Machine-The Iron Butcher" and the "Automated Machine for Grading herring Roe." The first machine uses a sophisticated camera to determine the cutting position of a fish, and moves the cutter and actuates it to perform the cutting operation accurately and fast, with least wastage of meat. The second machine utilizes an intelligent sensor system (through sensor fusion) to determine the size, shape, color, and texture of herring roe (the egg sac of the fish herring) and grade them accordingly into several bins. Herring roe is a delicacy in Japan to which most of the product from Canada is exported.

Even though my PhD at MIT was in Automated Guided Transit Systems, my nine-year tenure as an Assistant Professor and Associate Professor at Carnegie Mellon University in Pittsburgh, USA, provided me an opportunity to carry out research in robotics. In fact I was one of the six faculty members, headed by Prof. Raj Reddy, who flew to Westinghouse Electric Co in Winston Salem, North Carolina in the late 1970s to solicit funds for establishing the now world-famous Robotics Institute at Carnegie Mellon. Westinghouse had given us two small airplanes for the trip. I took the single-engine plane with two others and left first. The rest of the team, with Raj Reddy, followed us in the twin-engine plane. That plane had not arrived more than 30 minutes after we landed in Winston Salem. When we checked, we were told that the plane had to return to Pittsburgh because it had experienced an engine malfunction. They arrived several hours later, and our meeting with Westinghouse went quite well. Initially, my research in robotics involved new control techniques for robots; in particular, imparting human intelligence into robot control. Also I, with NASA Langley and Lewis Research Centers, led the development of new drive joints, sensors, and controllers for robots, including space-station robots; for example, a friction-drive joint, a joint torque sensor, and a reactionminimization controller.

At the University of British Columbia I continued my research and development in robotics. Now my work primarily involves mobile 
robots. For example, one project develops cooperative robotic groups for human rescue in disaster situations. Here, when an emergency situation (e.g., explosion, chemical spill) arises, robots in the neighborhood (in a city of the future) who are engaged in their routine work (e.g., trash collection, surveillance, traffic control, assisting the elderly and the disabled) are notified of the situation through a sensor network. The available robots proceed to the emergency site, scan the environment, negotiate among themselves, and carry out the required tasks (e.g., moving the injured people, giving first aid, constructing basic devices using parts available in the scene to assist in the required tasks) in a cooperative manner.

Another project develops a homecare robotic system for the elderly and the disabled. Here, the household will have one or more dedicated robots. They will assist the occupants with their day to day routine tasks (e.g., cleaning, delivery of food and medication, assisting in human mobility). When an accident happens, the sensor system in the house automatically notifies various authorities (e.g., hospital emergency room, police, fire department) and also will assist in the situation in the best possible way. These robots may be operated remotely as well (using haptic teleoperation from a hospital control room by a doctor or a nurse) to provide emergency assistance while the help is on the way.

A third project that is carried out in my lab develops a system to automatically improve the design of an existing machine. In this framework, a system for monitoring the machine health, a system for modeling the machine (which uses linear graphs), an expert system that possesses the expertise of human experts on machine design, and an evolutionary optimization system (which uses genetic programming) collaborate in identifying design weaknesses in the machine and coming up with better and better designs for the machine in an evolutionary manner (see Figure). I have elaborated on these topics yesterday in my technical talk at OUSL. 


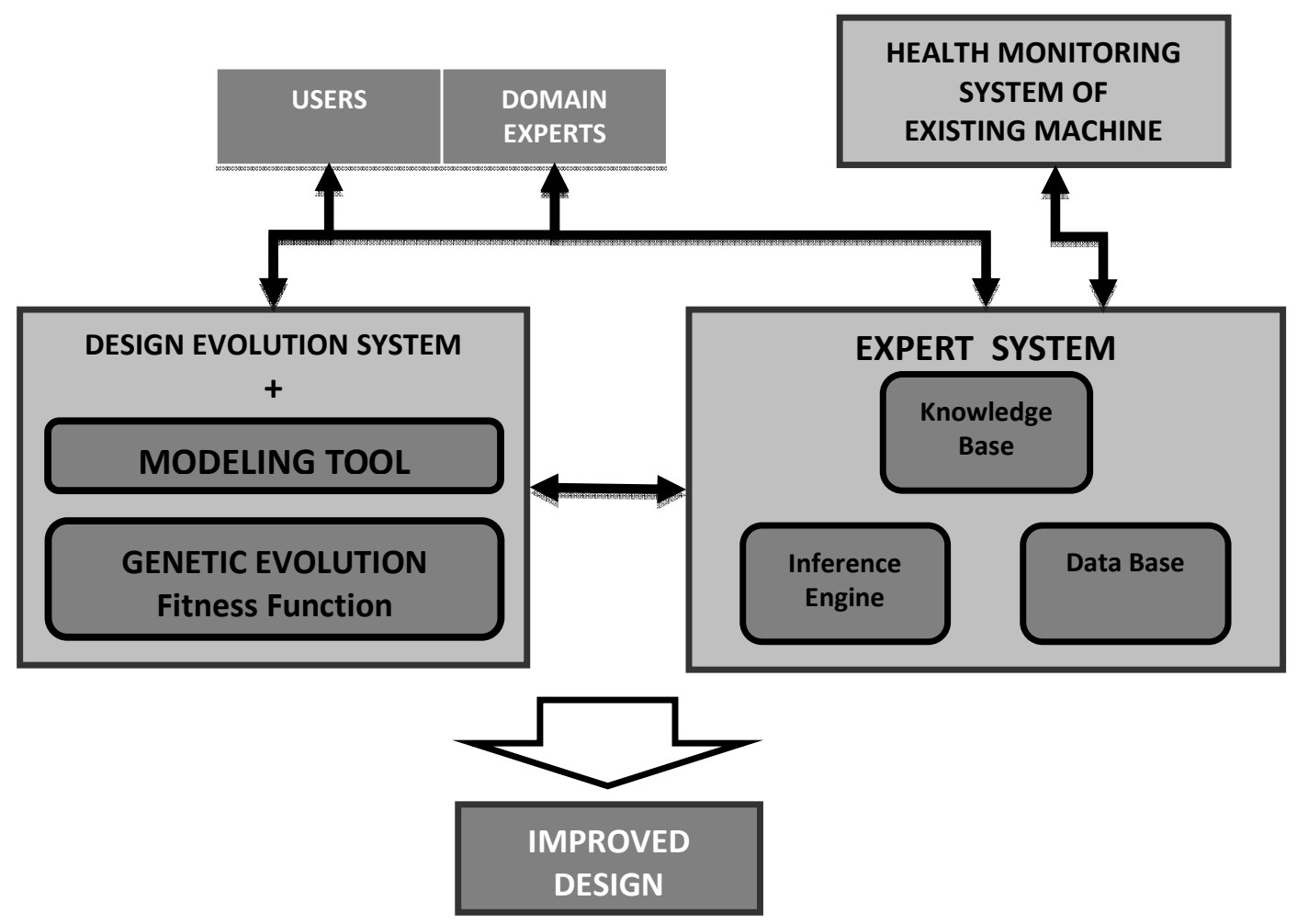

Figure System Framework for Automatic Design Evolution.

\section{Acknowledgements}

Before I conclude, I wish to express my deep appreciation for those who worked hard to award me this honorary D.Sc. degree. I value it as much as I do my "earned" degrees.

Let me conclude by paying tribute to my parents who helped me achieve my purpose in life; my wife for her love, support, and scrutiny as always; my children for making life worth living; my teachers for believing in me; and my students for teaching me the things that I did not have time to learn, technical or otherwise.

Thank You, May the Triple Gem Guide You, and May God Bless You! 